\title{
Impact of the COVID-19 Pandemic on the Air Quality in Delhi, India
}

\author{
Apurva Goel $\dagger$ \\ Department of Environmental Studies, H.V. Desai College, Pune, Maharashtra, India \\ †Corresponding author: Apurva Goel; apurva.goel@gmail.com
}

Nat. Env. \& Poll. Tech.

Website: www.neptjournal.com

Received: 05-05-2020

Accepted: 11-06-2020

Key Words:

COVID-19

Lockdown

Pandemic
Revised: 25-05-2020

Ambient air quality

\begin{abstract}
The COVID-19 pandemic is one of the biggest health calamities that the world has faced, which has infected millions of people and lead to hundreds of thousands of deaths all over the world. It has impacted the economic, social and health aspects of the countries to quite an extreme level. But an indirect positive impact can also be seen on the environment. In this paper, taking the example of Delhi, one of the most polluted cities of India, an analysis has been done to compare the levels of air pollutants (PM2.5, PM10, NOx and ozone) during the lockdown and the same period in the previous years. The study shows that the extent to which the industries, vehicles, power plants etc. release the air pollutants and severely impact the environment and human health. As during the lockdown when all such activities were either stopped or very much restricted, a reduction of almost $60 \%$ in the particulate matter pollution and up to $40 \%$ in the NOx pollution was observed while the ozone levels were reduced by $30-40 \%$ as compared to the same period during the previous two years. In the end, some suggestions have been made which can play some part to control air pollution once the lockdown is over.
\end{abstract}

\section{INTRODUCTION}

The year 2020 began with the world facing one of the most devastating health calamities of the century, i.e. COVID 19 pandemic, killing lakhs of people around the world. It has become the greatest challenge for the governments of all the countries including the giant nations like USA, UK, China, Russia, etc. to save their people from getting succumbed to this life-threatening virus. The reports of the spreading the Corona Virus Disease (COVID) among the human population first emerged from Wuhan in the Hubei Province of China in December 2019 (Huang et al. 2020). Soon within 2-3 months, the virus had spread to almost all parts of the world. Till date, millions of people have been infected by this virus causing hundreds of thousands of deaths. The countries which are most affected include the United States, Spain, Russia, United Kingdom, Italy, Brazil and many more.

The virus spreads when an infected person coughs or sneezes and droplets are thrown out in the air. These droplets can land on different surfaces which can be picked up by any person who touches that surface and then touches the nose, mouth or eyes (Rothan \& Byrareddy 2020). As per the World Health Organization (WHO 2020), the most important thing to protect oneself from the virus is to keep the hands clean by washing them properly with soap at regular intervals or when exposed to anything from outside or any person. Social distancing is another way by which the community spread of the Coronavirus can be controlled (Lewnard \& Lo 2020).
With these guidelines, the countries have taken various measures to protect their people from this pandemic. Some of the measures include the shutting down of the international and domestic travel; shutting down of schools, offices, industries; complete lockdown of people in their houses, shutting down the public transport, etc. These steps have helped in controlling the spread of the virus, but it has brought the entire world's economy under the threat of high inflation, loss in productivity, migration of labours, unemployment and excessive expenditure on the health care systems for the treatment of the COVID-19 victims.

In India, the Prime Minister of India had announced a strict Nationwide lockdown for its 1.3 billion population from $24^{\text {th }}$ March 2020 as a preventive measure against the COVID 19 pandemic (Pulla 2020). All the institutions, industries, highways including the markets, shops public places were all closed, while only a few basic necessity shops like dairy, grocery, medical and fruits and vegetables were allowed to be open, but only for a certain period during the day. People were asked to stay at home and only come out for buying essentials during the allotted time slot maintaining social distancing (Lancet 2020). Though this step helped India to control the graph of the COVID-19 cases, there were many negative impacts also which people had to face, especially the below poverty class people and the labours whose only source of income is their daily wages. The government of India has taken all necessary measures to help the poor by 
providing them with the basic goods of necessity and free food, but still, the help could not be reached to $100 \%$ of the needy people due to many limitations.

The COVID-19 pandemic has impacted not only the health aspect, but it has also impacted the social, economic and environmental aspects of all the countries (McKibbin \& Fernando 2020, Chakraborty \& Maity 2020). An indirect effect of the COVID-19 pandemic can also be seen on the environment, but this impact is a positive one (Zambrano-Monserrate et al. 2020). Due to the outbreak of the COVID-19, people are forced to stay at home due to the lockdown and has also resulted in the closure of all the industries, institutions and reduction in the vehicular movement. This has proved to be very beneficial for the environment. Due to the non-functioning of the industries, the waste emission, which is a major cause for the water and air pollution, has decreased to a very large extent. Again, as there are very restricted movements of the vehicles on road, the NOx, PM2.5 and greenhouse gases emissions have also reduced to a great extent (Sharma et al. 2020). People can breathe clean air and even experiencing clear sky, due to the absence of smog, for the first time in many years (Sinha \& Saran 2020). As the tourists are not found on the beaches, hill stations and jungles, land pollution has also reduced in such places.

In this paper, the author has analysed the environmental impact on the air pollution levels in India during the lockdown period due to the COVID-19 pandemic. To determine the impact on the air pollution, Delhi was taken as the area of study and the air quality data for PM2.5, PM10, NOx and ozone levels from 5 monitoring stations were compared with the levels in the previous year. Some suggestions are also recommended which if implemented can play some role in controlling the air pollution once the lockdown of the nation is over.

\section{MATERIALS AND METHODS}

For the analysis of the air quality during the lockdown, Delhi has been taken as the study area. Delhi is the national capital of India located at $28.61^{\circ} \mathrm{N} 77.23^{\circ} \mathrm{E}$. Delhi holds the second position in the list of the megacities of the world ((United Nations 2018). Delhi being one of the most polluted cities of the country and ranking (Hariharan 2019) on the global scale is an ideal area for the study. Five monitoring stations (Ashok Vihar-DPCC, DTU - CPCB, IGI Airport (T3)-IMD, Wazirpur and Najafgarh) were selected (Fig. 1) and the data reported from these stations were taken from the CPCB website (https://app.cpcbccr.com/ccr/\#/caaqm-dashboard/ caaqm-landing) for the year 2018, 2019, 2020 during February, March and April. The 24-hour average concentration of 4 major pollutants i.e., PM2.5, PM10, NOx and Ozone has been obtained and analysed. The February and March (up to 23rd) were the non-lockdown periods while April is the complete lockdown period. The current data were compared with the data of the same period in the previous years, i.e. 2018 and 2019, as the air quality largely depends on the seasonal conditions. The monitoring stations were selected on

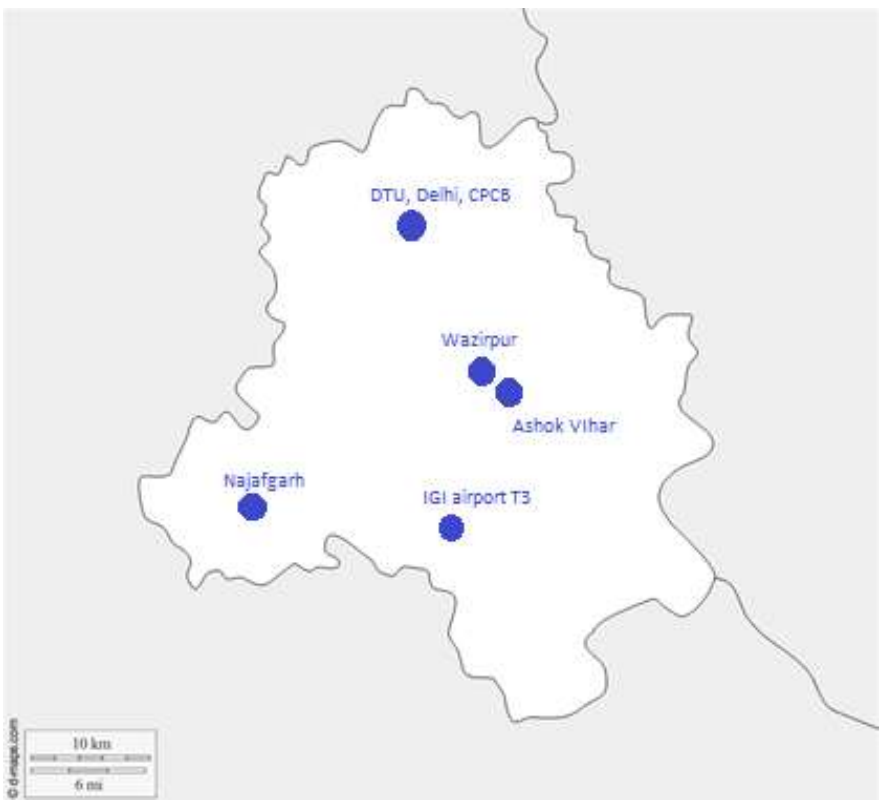

Fig. 1: Locations of the monitoring stations. 
the basis on the data availability, level of pollution reported by them and cover the wider area of the city.

\section{RESULTS}

\section{Particulate Matter}

Particulate matter is a mixture of solid particles and liquid droplets in the air, some of which can be seen through the naked eye, while some are so small that they could only be detected through an electron microscope. These include the dust, dirt, soot, smoke and drops of liquids. Based on the size of the particles they are divided into PM2.5 and PM10.

Particulate matter poses a great risk to human health. PM10 can irritate the eyes, nose and throat. Particles that are very fine, i.e. PM2.5 are more dangerous as these can mix with the bloodstream and even go deep into the lungs. They are many times associated with lung cancer also.

Tables 1 and 2 show the average monthly values of the PM2.5 and PM10 respectively, for February, March and April in the year 2018, 2019 and 2020. It can be from the data that during the month of April 2020, i.e the lockdown period, the PM2.5 values are ranging between $40-50 \mu \mathrm{g} / \mathrm{m}^{3}$, which is below the National Ambient Air Quality Standard (NAAQS) value of $60 \mu \mathrm{g} / \mathrm{m}^{3}$, while the readings for all the other periods is way beyond the standard value. Similarly, the PM10 values are ranging between the $90-140 \mu \mathrm{g} / \mathrm{m}^{3}$, which is just closer to the NAAQS standard value of 100 $\mu \mathrm{g} / \mathrm{m}^{3}$, while all the other readings are almost 2 or 3 times the standard value.

The values of the current year are compared with the previous two years and the per cent reduction in the values during the lockdown, i.e. for April was determined (Tables $3 \& 4)$.

As can be seen from Table 5 and Fig. 2, there has been a substantial decrease in the PM2.5 pollutants in the air during April 2020 due to the lockdown. The maximum decrease of $50.95 \%$ was found at station DTU-CPCB. Similarly, from Table 4 and Fig. 3, a maximum decrease of $68.04 \%$ in the PM10 value was at the station Wazirpur.

\section{NOx}

Nitrogen oxides is a collective term used for the nitrogen monoxide (NO) and nitrogen dioxide $\left(\mathrm{NO}_{2}\right)$. These gases are emitted in the air mainly from the fuel combustion in vehicles, power plants and industries. Previous studies have reported that almost $80-90 \%$ for the NOx and CO pollutants are produced from the transport sector in the Delhi Region (Gurjar et al. 2004, Tyagi et al. 2016).

NOx react in the atmosphere to form smog and acid rain. Breathing air in such an environment can cause respiratory problems, damage the lung tissues and other breathing-related problems in humans. Acid rain is also very dangerous to both plants and human beings.

Tables 5 shows the average monthly values of the NOx, for February, March and April in the year 2018, 2019 and 2020 . The values of the current year were compared with the previous two years and the per cent reduction in the values during the lockdown, i.e. for April was determined (Table 6).

It can be observed from Table 6 and Fig. 4, that a significant decrease in the NOx occurs during April. A maximum reduction of $70.75 \%$ was reported from the Ashok Vihar-DPCC

Table 1: PM2.5 monthly average values for the 5 monitoring stations in $\mu \mathrm{g} / \mathrm{m}^{3}$.

\begin{tabular}{|c|c|c|c|c|c|c|c|c|c|c|c|c|c|c|c|}
\hline \multirow[t]{2}{*}{ Year } & \multicolumn{3}{|c|}{ Ashok Vihar-DPCC } & \multicolumn{3}{|c|}{ DTU - CPCB } & \multicolumn{3}{|c|}{ IGI Airport (T3) - IMD } & \multicolumn{3}{|c|}{ Wazirpur - DPCC } & \multicolumn{3}{|c|}{ Najafgarh - DPCC } \\
\hline & Feb & March & Apr & Feb & March & Apr & Feb & March & Apr & Feb & March & Apr & Feb & March & Apr \\
\hline 2018 & 172.04 & 119.95 & 101.38 & 169.76 & 122.81 & 87.84 & 161.80 & 69.20 & 59.18 & 162.85 & 120.14 & 99.064 & 123.40 & 94.10 & 76.08 \\
\hline 2019 & 141.68 & 92.43 & 95.33 & 118.77 & 92.81 & 84.62 & 168.20 & 72.43 & 69.23 & 166 & 98.355 & 101.44 & 110.17 & 83.86 & 68.17 \\
\hline 2020 & 134.55 & 67.73 & 48.59 & 152.58 & 76.39 & 50.93 & 214.82 & 48.34 & 39.07 & 146.49 & 71.972 & 52.392 & 112.08 & 66.54 & 47.13 \\
\hline
\end{tabular}

Table 2: PM10 monthly average values for the 5 monitoring stations in $\mu \mathrm{g} / \mathrm{m}^{3}$.

\begin{tabular}{|lllllllllllllllll|}
\hline Year & \multicolumn{3}{c}{ Ashok Vihar-DPCC } & \multicolumn{3}{c}{ DTU - CPCB } & \multicolumn{3}{c|}{ IGI Airport (T3) - IMD } & \multicolumn{4}{c|}{ Wazirpur - DPCC } \\
\hline & Feb & March & Apr & Feb & March & Apr & Feb & March & Apr & Feb & March & Apr & Feb & March & Apr \\
\hline 2018 & 330.68 & 286.48 & 315.21 & NA & 385.35 & 299.36 & 241.80 & 143.30 & 175.87 & 365.42 & 287.82 & 371.52 & 212.95 & 216.16 & 269.90 \\
2019 & 236.55 & 193.65 & 167.72 & 203.57 & 194.84 & 263.70 & 251.23 & 176.59 & 224.13 & 295.39 & 231.58 & 307.84 & 167.52 & 145.23 & 191.96 \\
2020 & 230.35 & 121.84 & 95.15 & 285.28 & 154.61 & 123.80 & 343.10 & 116.33 & 88.02 & 272.28 & 170.07 & 108.57 & 175.57 & 133.68 & 143.72 \\
\hline
\end{tabular}




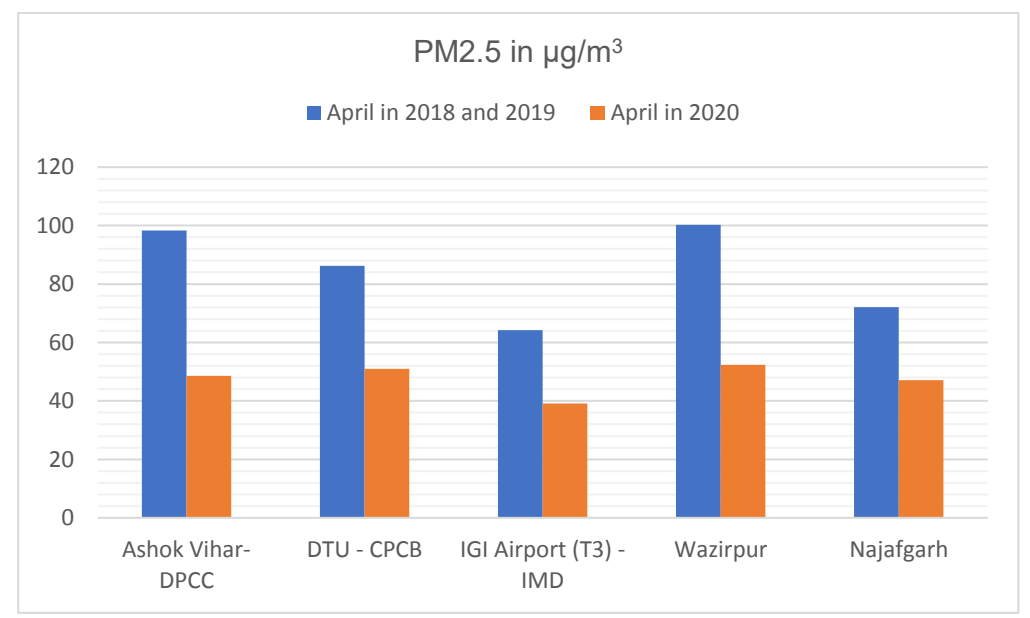

Fig. 2: The PM2.5 values in April 2020 compared to the average of 2018 and 2019 for the same period.

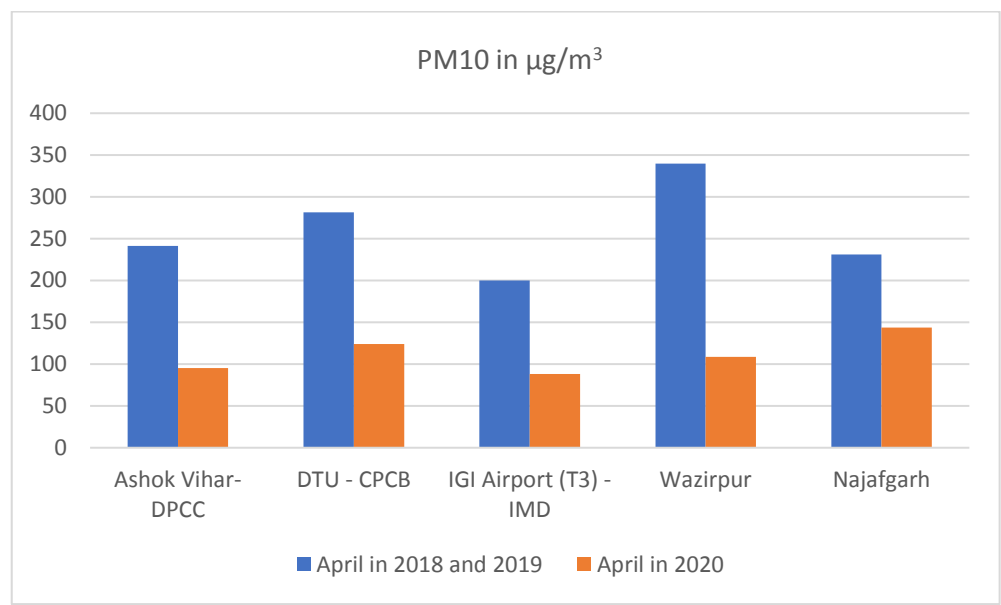

Fig. 3: The PM10 values in April 2020 compared to the average of 2018 and 2019 for the same period.

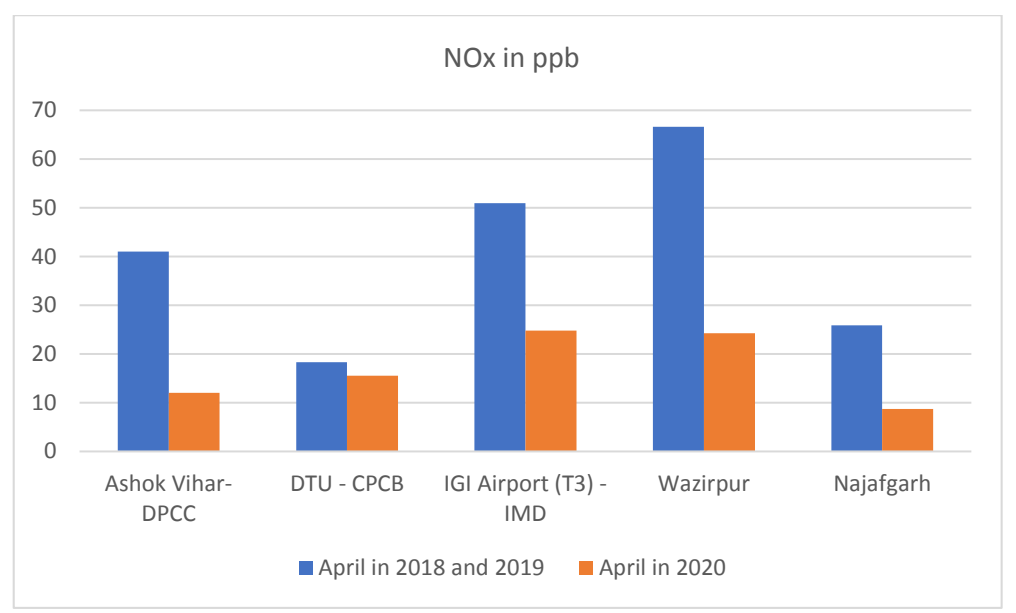

Fig. 4: The NOx values in April 2020 compared to the average of 2018 and 2019 for the same period. 
Table 3: Per cent reduction in the PM2.5 in April in 2020 compared to the average of the 2018 and 2019 April values.

\begin{tabular}{|llll|}
\hline Stations & $\begin{array}{l}\text { Average of the Year } 2018 \text { and } 2019 \text { for } \\
\text { April }\left(\mu \mathrm{g} / \mathrm{m}^{3}\right)\end{array}$ & Value in April $2020\left(\mu \mathrm{g} / \mathrm{m}^{3}\right)$ & $\%$ Reduction \\
\hline Ashok Vihar-DPCC & 98.35 & 48.59 & 50.59 \\
DTU-CPCB & 86.23 & 50.93 & 40.94 \\
IGI Airport (T3)-IMD & 64.21 & 39.07 & 39.15 \\
Wazirpur & 100.25 & 52.39 & 47.74 \\
Najafgarh & 72.13 & 47.13 & 34.66 \\
\hline
\end{tabular}

Table 4: Per cent reduction in the PM10 in April in 2020 compared to the average of the 2018 and 2019 April values.

\begin{tabular}{|llll|}
\hline Stations & Average of the Year 2018 and $2019\left(\mu \mathrm{g} / \mathrm{m}^{3}\right)$ & Value in April $2020\left(\mu \mathrm{g} / \mathrm{m}^{3}\right)$ & $\%$ Reduction \\
\hline Ashok Vihar-DPCC & 241.45 & 95.15 & 60.59 \\
DTU-CPCB & 281.53 & 123.8 & 56.03 \\
IGI Airport (T3)-IMD & 200 & 88.02 & 55.99 \\
Wazirpur & 339.68 & 108.57 & 68.04 \\
Najafgarh & 230.93 & 143.72 & 37.76 \\
\hline
\end{tabular}

Table 5: NOx monthly average for the 5 monitoring stations in ppb.

\begin{tabular}{|llllllllllllllllll}
\hline Year & \multicolumn{3}{c}{ Ashok Vihar-DPCC } & \multicolumn{3}{c}{ DTU - CPCB } & \multicolumn{4}{c}{ IGI Airport (T3) - IMD } & \multicolumn{4}{c}{ Wazirpur } \\
\hline & Feb & March & Apr & Feb & March & Apr & Feb & March & Apr & Feb & March & Apr & Feb & March & Apr \\
\hline 2018 & 56.63 & 41.99 & 37.21 & 48.76 & 31.25 & 8.76 & 114.57 & 46.88 & 53.81 & 65.009 & 60.015 & 54.104 & 31.91 & 28.50 & 31.14 \\
2019 & 57.18 & 50.88 & 44.71 & 41.74 & 27.86 & 27.79 & 164.89 & 78.44 & 48.03 & 92.537 & 72.173 & 79.074 & 32.87 & 24.82 & 20.60 \\
2020 & 51.13 & 32.11 & 11.98 & 30.10 & 19.24 & 15.53 & 96.43 & 74.02 & 24.77 & 68.597 & 47.143 & 24.246 & 24.08 & 16.96 & 8.71 \\
\hline
\end{tabular}

monitoring station. A satellite image (Fig. 5) showing the average concentration of nitrogen dioxide over India during the period of $1^{\text {st }}$ January to $24^{\text {th }}$ March and $25^{\text {th }}$ March to $20^{\text {th }}$ April for the year 2019 and 2020 also shows the reduction in the concentration of the $\mathrm{NO}_{2}$ during the lockdown.

\section{Ozone}

Ozone found in the stratosphere is good ozone as it protects the earth from the harmful ultraviolet rays. But the ground-level ozone is bad for humans as it has a negative effect on human health. Ozone is not a primary pollutant as it is not directly emitted by the sources. It is a secondary pollutant formed due to the photochemical reactions of NOx and VOCs in the presence of sunlight.

Inhalation of ozone causes breathing problems, coughing, chest pain, throat irritation, damage of lung tissues and other health issues.

Table 7 shows the average monthly values of the ozone, for February, March and April in the year 2018, 2019 and 2020. The values of the current year were compared with the previous two years and the per cent reduction in the values during the lockdown, i.e. for April was calculated (Table 8).

Table 8 and Fig. 6 shows that there has been a good reduction in the ozone concentration during the lockdown period in four out of five stations [an exception being the DTU-CPCB station which may be due to lesser reduction in the NOx levels (15\%)]. Studies have shown that the reduction in VOCs is more effective in limiting ozone production as compared to the NOx (Jhun et al. 2015).

\section{DISCUSSION}

The lockdown has restricted the commercial activities, construction activities, vehicular movement and industrial activities which are the major contributor to the air pollutants. From the above analysis, we can see that there has been a significant decrease in the concentration of major pollutants like PM2.5, PM10, NOx and ozone in the air during the lockdown period due to the Covid-19. This result is consistent with a study by Sharma et al. (2020) who reported a maximum reduction of $49 \%$ in AQI in Delhi. The AQI in Delhi has always been under the 'very poor' to 'severe' category due to which the people are under constant threat of health 
Table 6: Percentage reduction in the NOx in April in 2020 compared to the average of the 2018 and 2019 April values.

\begin{tabular}{|llll|}
\hline Stations & Average of the Year 2018 and 2019 $(\mathrm{ppb})$ & Value in April 2020 (ppb) & $\%$ Reduction \\
\hline Ashok Vihar-DPCC & 40.96 & 11.98 & 70.75 \\
DTU-CPCB & 18.28 & 15.53 & 51.36 \\
IGI Airport (T3)-IMD & 50.92 & 24.77 & 63.58 \\
Wazirpur & 66.59 & 24.25 & 66.33 \\
Najafgarh & 25.87 & 8.71 & \\
\hline
\end{tabular}

Table 7: Ozone monthly average for the five monitoring stations in $\mu \mathrm{g} / \mathrm{m}^{3}$.

\begin{tabular}{|lllllllllllllllllll}
\hline Year & \multicolumn{4}{l}{ Ashok Vihar-DPCC } & \multicolumn{3}{c}{ DTU - CPCB } & \multicolumn{2}{c|}{ IGI Airport (T3) - IMD } & \multicolumn{4}{c}{ Wazirpur } \\
\hline & Feb & March & Apr & Feb & March & Apr & Feb & March & Apr & Feb & March & Apr & Feb & March & Apr \\
2018 & 34.90 & 47.78 & 62.54 & NA & 0.02 & 9.21 & 101.50 & 31.54 & 36.14 & 26.012 & 33.988 & 46.134 & 50.05 & 60.07 & 79.13 \\
2019 & 30.03 & 39.37 & 45.96 & 34.77 & 41.47 & 54.30 & 99.33 & 23.15 & 25.59 & 22.221 & 33.985 & 45.08 & 47.74 & 55.93 & 78.15 \\
2020 & 27.95 & 27.81 & 36.42 & 47.32 & 52.62 & 78.77 & 113.08 & 13.57 & 25.92 & 11.424 & 4.8438 & 33.059 & 39.05 & 44.78 & 38.17 \\
\hline
\end{tabular}

Table 8: Per cent reduction in the Ozone in April in 2020 compared to the average of the 2018 and 2019 April values.

\begin{tabular}{|llll|}
\hline Stations & Average of the Year 2018 and $2019\left(\mu \mathrm{g} / \mathrm{m}^{3}\right)$ & Value in April $2020\left(\mu \mathrm{g} / \mathrm{m}^{3}\right)$ & $\%$ Reduction \\
\hline Ashok Vihar-DPCC & 54.25 & 36.42 & 32.87 \\
DTU-CPCB & 31.76 & 78.77 & -148.02 \\
IGI Airport (T3)-IMD & 30.87 & 25.92 & 16.03 \\
Wazirpur & 45.6 & 33.059 & 27.50 \\
Najafgarh & 78.64 & 38.17 & 51.46 \\
\hline
\end{tabular}

issues. During the lockdown, the AQI in Delhi has reached to 'satisfactory' to 'moderate' category.

This shows the extent to which the anthropogenic activities are responsible for the increase in the concentration of pollutants in the air, due to which the air quality is becoming worst for human beings. There has been an increasing number of health issues which people are facing in the urban areas as they are continuously forced to breathe in polluted air (Pandey \& Devotta 2005). These pollutants are also the reason for the major global issues like climate change and global warming (Alcamo et al. 2002).

Restricting the anthropogenic activities causing the release of pollutants in the air, can be an ideal solution to the control of air pollution, but slowing down the economy and growth of the country is not a kind of solution that would be feasible for any country. Various other measures can be taken to put a control on them which in turn will help in reducing the concentration of harmful pollutants in the environment.

1. During the lockdown, wherever possible, people are working from home as they cannot travel. Organizations which never allowed the work from home model earlier have now accepted this model and allowing the employees to work from home. The feedback received is that there has been no impact on work front especially for the IT industry and the ones whose majority of the work is on the computers (Mitta 2020). If this model is continued, and employees are asked to come to the office only when needed, there would be major drop vehicular movement. The companies can also opt for a $50 \%$ work from a home model, where $50 \%$ of their workforce is always working from home. As reported by $\mathrm{CPCB}$, the vehicular contribution to the total urban air pollution in Delhi and Mumbai is about $76-90 \%$ for $\mathrm{CO}, 66-74 \%$ for $\mathrm{NOx}, 5-12 \%$ for $\mathrm{SO}_{2}$ and $3-12 \%$ for PM (Gulia et al., 2015).

2. Majority of the offices, including the government offices are using the video conferencing for their meetings during the lockdown. If people start using it for their Meetings regularly, their travel will reduce which will bring down the number of vehicles on the road.

3. The industries cannot be stopped from their operations, but strict action can be taken on the control of its emissions. The government should imply stricter rules and impose stringent monitoring on the emissions emitted by the industries. 


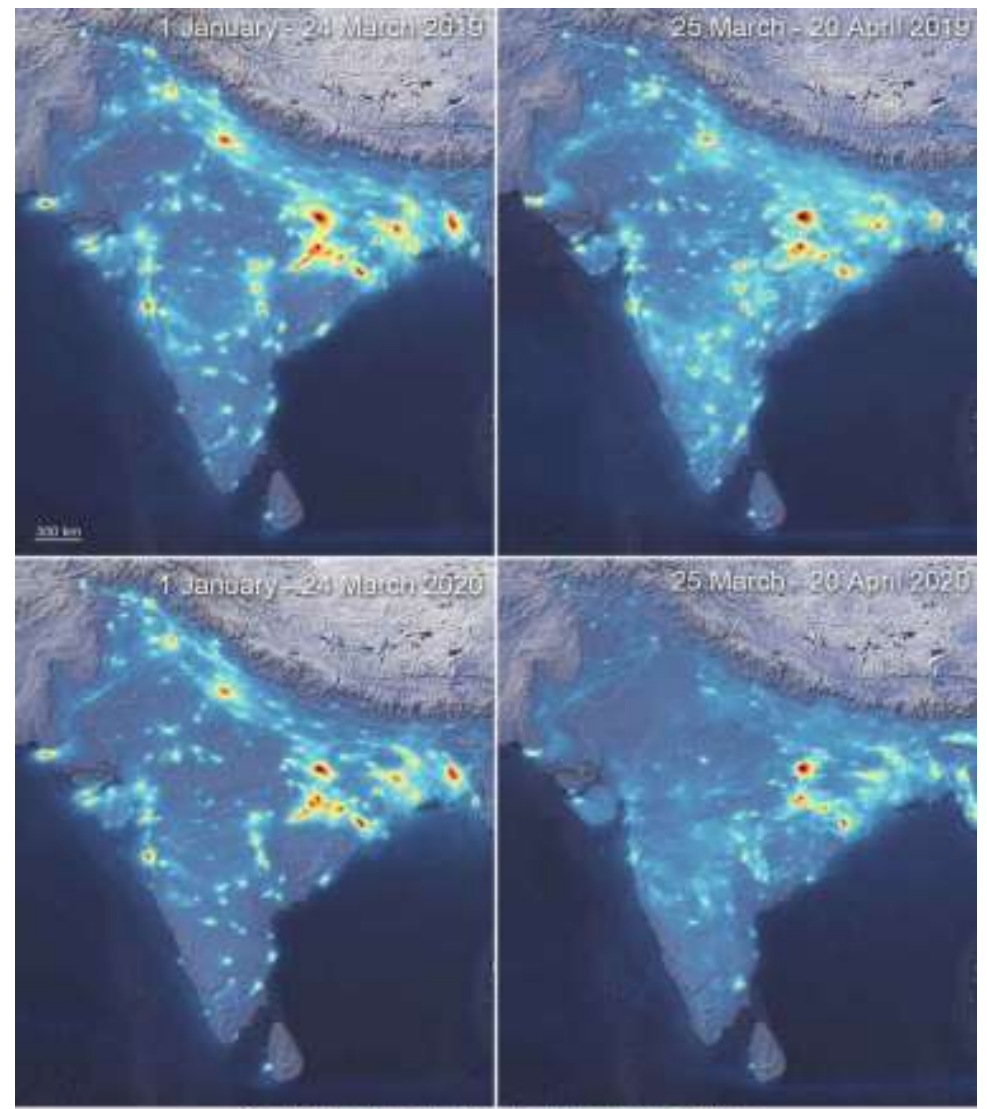

Sentinel-5P Nitrogen Dioxide tropospheric column

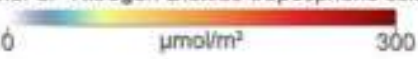

Fig. 5: Satellite image showing the average nitrogen dioxide over India. Source: ESA/Copernicus

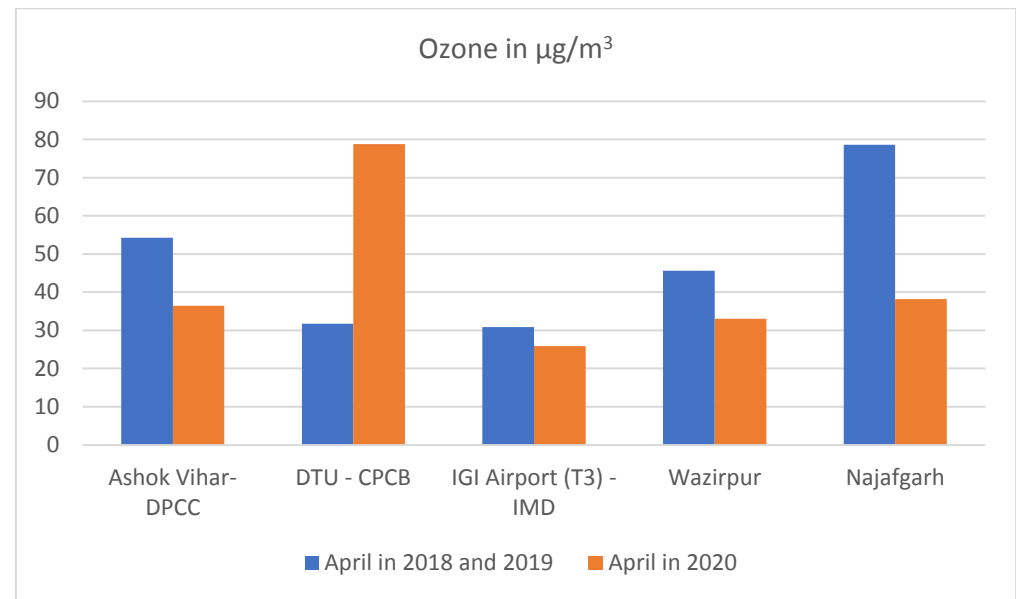

Fig. 6: The ozone values in April 2020 compared to the average of 2018 and 2019 for the same period. 
4. During the lockdown, the government has imposed a model where people do not need to travel to places for necessities like groceries, fruits, vegetables and medicines but these necessities have been reached out to them at their places. If this model can continue even after lockdown, wherever feasible, it will surely contribute to lessening the air pollutants. More virtual online supermarkets should be introduced so that their services could reach more and more people. People should be given special discounts and perks to encourage them to use online markets instead of travelling and going to the markets.

5. Many service industries have started their online working model to continue to provide their services to customers. They should think of continuing this model even after the lockdown as this will decrease the travel of the people.

\section{CONCLUSION}

The Covid-19 pandemic has shaken the entire world with hundreds of thousands of deaths and millions of people affected due to this virus. It has impacted the economy, health care systems and the social life of people. Most of the countries have shut down the institutions, industries and transport and asked people to stay at home to control the spread of the virus.

The only positive side that be seen during this difficult time is the impact on the environment. With the reduced anthropogenic activities causing pollution, the environment is breathing easily during this period. Taking Delhi, as the study area, different parameters (PM2.5, PM10, NOx and ozone) of five monitoring stations were analysed and compared with the values in the previous year. The results show that there has been a considerable reduction in the concentration of air pollutants in the air. A reduction of almost up to $50 \%$ was found in the PM2.5 values, while the PM10 values showed a reduction of up to $68 \%$ and the NOx values showed a reduction of up to $70 \%$.

Everyone knows that this is a temporary effect and pollution level will become regular after the lockdown is over. But it is time to give a thought to the level at which the environment is getting affected due to the uncontrolled human activities. If these activities cannot be stopped completely, they can definitely be reduced. The lockdown period has introduced many different models of working, education and business which require none or very less travel. People should seriously think on such models to continue which is going to reduce the vehicular movements and in turn reduce the emission of pollutants in the air. The regulatory bodies should also take this experience as a very good example and work on different plans to impose strict regulations on the emissions from the industries and power plants.

\section{REFERENCES}

Alcamo, J., Mayerhofer, P., Guardans, R., van Harmelen, T., van Minnen, J., Onigkeit, J., Posch, M. and de Vries, B. 2002. An integrated assessment of regional air pollution and climate change in Europe: Findings of the AIR-CLIM Project. Environmental Science \& Policy, 5(4): 257-272.

Chakraborty, I. and Maity, P. 2020. COVID-19 outbreak: Migration, effects on society, global environment and prevention. Science of The Total Environment, 728: 138882.

Gulia, S., Nagendra, S.S., Khare, M. and Khanna, I. 2015. Urban air quality management-A review. Atmospheric Pollution Research, 6(2): 286-304.

Gurjar, B.R., Van Aardenne, J.A., Lelieveld, J. and Mohan, M. 2004. Emission estimates and trends (1990-2000) for megacity Delhi and implications. Atmospheric Environment, 38(33): 5663-5681.

Huang, C., Wang, Y., Li, X., Ren, L., Zhao, J., Hu, Y., Zhang, L., Fan, G., Xu, J., Gu, X. and Cheng, Z. 2020. Clinical features of patients infected with 2019 novel coronavirus in Wuhan, China. The lancet, 395(10223): 497-506.

Jayant Sinha \& Samir Saran 2020. View: In the lockdown, a breath of fresh air View: In the lockdown, a breath of fresh air. The Economic Times, May 08, 2020. https://economictimes.indiatimes.com/news/ politics-and-nation/view-in-the-lockdown-a-breath-of-fresh air/ articleshow/75635142.cms?utm_source=contentofinterest\&utm_medium=text\&utm_campaign=cppst

Jhun, I., Coull, B.A., Zanobetti, A. and Koutrakis, P. 2015. The impact of nitrogen oxides concentration decreases on ozone trends in the USA. Air Quality, Atmosphere \& Health, 8(3): 283-292.

Lancet, T. 2020. India under COVID-19 lockdown. Lancet (London, England), 395(10233): 1315.

Lewnard, J.A. and Lo, N.C. 2020. Scientific and ethical basis for social-distancing interventions against COVID-19. The Lancet. Infectious diseases, 20(6): 631.

McKibbin, W. and Fernando, R. 2020. The economic impact of COVID-19. Economics in the Time of COVID-19: 45.

Mitta, Sridhar 2020. Work from home has been 'successful' during Covid-19 lockdown. What next? https://economictimes.indiatimes. com/magazines/panache/work-from-home-has-been-successful-during-covid-19-lockdown-what-next/articleshow/75470580.cms?utm_ source $=$ contentofinterest\&utm_medium $=$ text\&utm_campaign $=$ cppst

Pandey, J.S., Kumar, R. and Devotta, S., 2005. Health risks of $\mathrm{NO}_{2}$, $\mathrm{SPM}$ and $\mathrm{SO}_{2}$ in Delhi (India). Atmospheric Environment, 39(36): 6868-6874.

Pulla, P. 2020. Covid-19: India imposes lockdown for 21 days and cases rise. BMJ, 368: $\mathrm{m} 1251$

Revathi Hariharan 2019. Delhi is the most polluted city in the world today, says air quality report. https://www.ndtv.com/india-news/ delhi-is-the-most-polluted-city-in-the-world-today-says-air-qualityreport-2124800

Rothan, H.A. and Byrareddy, S.N. 2020. The epidemiology and pathogenesis of coronavirus disease (COVID-19) outbreak. Journal of Autoimmunity, 102433.

Sharma, S., Zhang, M., Gao, J., Zhang, H. and Kota, S.H. 2020. Effect of restricted emissions during COVID-19 on air quality in India. Science of The Total Environment, 728: 138878. 
Tyagi, S., Tiwari, S., Mishra, A., Hopke, P.K., Attri, S.D., Srivastava, A.K. and Bisht, D.S. 2016. Spatial variability of concentrations of gaseous pollutants across the National Capital Region of Delhi, India. Atmospheric Pollution Research, 7(5): 808-816.

United Nations Department of Economic and Social Affairs 2018. Revision of World Urbanization Prospects. United Nations Department of Economic and Social Affairs, New York.
WHO 2020. World Health Organization Clinical Management of Severe Acute Respiratory Infection When Novel Coronavirus (2019-nCoV) Infection Is Suspected: Interim Guidance (2020). World Health Organization, Geneva. Zambrano-Monserrate, M.A., Ruano, M.A. and Sanchez-Alcalde, L. 2020. Indirect effects of COVID-19 on the environment. Science of The Total Environment, 728: 138813. 